\title{
ALGUNAS CONSIDERACIONES GEOPOLÍTICAS A PROPÓSITO DE LA UBICACIÓN DE LOS VALLES DE LACIANA Y BABIA DURANTE EL BAJO MEDIEVO: ¿EN ASTURIAS O EN LEÓN?
}

\author{
Pablo GARCÍA CAÑÓN \\ Universidad de Valladolid
}

\begin{abstract}
RESUMEN: El presente artículo se propone realizar un acercamiento histórico a la percepción geográfica y política, que las gentes de finales de la Edad Media tenían sobre la ubicación de los valles de Laciana y Babia en Asturias o en León.

PALABRAS CLAVE: Laciana, Babia, Asturias, León, ubicación geo-política.

ABSTRACT: The purpose of the present article is to make a historic approach to the geographical and political perception that people in the Late Middle Ages had about the location of the valleys of Laciana and Babia in Asturias or León.
\end{abstract}

KEY-WORDS: Laciana, Babia, Asturias, León, geographical and political location.

El encabezamiento de este trabajo puede hacer pensar que mi intención es políticamente hablando, la de sustraer / incorporar a León o a Asturias y viceversa el marco espacial que aquí se analiza. Nada más lejos de la realidad. Consideraba necesario referirme a estas cuestiones, debido a la cantidad de menciones que iban saliendo en el análisis documental que he llevado a cabo sobre este territorio y por las inquietudes que muchas de ellas me producían. Únicamente voy a presentar una serie de noticias procedentes de época medieval, que afectan fundamentalmente a los valles de Laciana y Babia, a través de las cuales se observa una cierta tendencia por parte de los contemporáneos a incluir esos valles en el Principado de Asturias, ¿Se trata de confusiones geográficas o por otro lado responde a una realidad y "sentimiento territorial"?

Que la Cordillera Cantábrica es la línea divisoria natural entre Asturias y León / o Asturias y la tierra llana de Castilla es un hecho evidente desde los primeros 
siglos de la Edad Media, lo que no está tan claro es a partir de donde arrancarían los límites divisorios entre ambos territorios dentro de la propia Cordillera ${ }^{1}$. Claro está que las fronteras geográficas fijas no existen y que en muchas ocasiones las culturales, históricas y sociales sobrepasan y se superponen a las primeras, formando parte muchas veces aquellas del imaginario colectivo ${ }^{2}$. Algo así debía de ocurrir en la Edad Media en los valles de Laciana y Babia con relación a su vinculación histórico-geográfica con Asturias.

En principio, la demarcación eclesiástica, que siempre respondía a criterios más racionales que las circunscripciones políticas, incluía salvo unas pocas excepciones

${ }^{1}$ Los textos de los siglos XI y XII individualizan la unidad geográfica de Asturias con una serie de límites naturales: "Asturias inter duo flumina, Ove et Deva, a Pirinei montes usque in ora maris", es decir: "Asturias entre dos ríos, Eo y Deva, desde los montes Pirineos hasta la orilla del mar",García Larragueta, S. A., (1962). Colección de documentos de la Catedral de Oviedo. Oviedo: Instituto de Estudios Asturianos, doc. $\mathrm{n}^{\circ} .61$ (1058, julio, 15). En ningún momento la documentación medieval especifica con claridad desde donde arrancarían exactamente los límites dentro de la propia Cordillera entre Asturias y el traspaís leonés, en todo caso, se refiere a las Pirinei Montes como un todo que sirve de delimitación. No obstante, también se hace necesario señalar que estos altos valles de Laciana y Babia no aparecen siempre encuadrados dentro del territorio Asturiense durante la Alta Edad Media, pues en la documentación de aquellos siglos aparecen enclavados con cierta frecuencia en el área denominada Foris Montes, es decir, al sur de la Cordillera Cantábrica. En cualquier caso, el significado tan difuso y periférico que poseía dicho término para designar los territorios enclavados entre los montes cantábricos, el Duero y el río Cea durante aquella época, "hace que se utilice para designar espacios tan amplios como vagos en sus contornos", SÁnChez BADIOLA, J. J. (2004), Las armas del reino y otros estudios de historia leonesa. León: Diputación Provincial de León, pp. 143-145. Actualmente es la divisoria de aguas que marcan los puertos secos, la frontera administrativa en la que se basa la delimitación entre el Principado de Asturias y la provincia de León, solamente en los valles de Sajambre y Valdeón no tiene correspondencia teórica esta división, ya que el avenamiento de ambos valles vierte sus aguas al río Sella y al Cares, quedando ya estos dentro del límite de aguas vertientes hacia Asturias.

2 Debido a las limitaciones materiales y temáticas de la presente investigación no vamos a profundizar por ejemplo en aspectos tan incuestionables como las similitudes culturales (dialectales, etnográficas...) existentes entre Laciana y Babia con los vecinos valles asturianos de Ibias, Degaña, Cerredo, Cangas de Narcea, Leitariegos, Somiedo, Teverga y Quirós, y que por otro lado ya se ha estudiado en algunos trabajos, por ejemplo: Álvarez Pérez, G., (1985). El habla de Babia y Laciana, reed., León: Ediciones Leonesas; Rodríguez Cosmen, M., (1982). El pachxuezu, habla medieval del occidente Astur-Leonés, León: Nebrija; Marentes Álvarez, C. / Criado Placín, L., (1987). (Grabación sonora realizada por la "Sociedad San Miguel de Bailes y costumbres de Laciana"), A xeito: música, canciones y bailes de la Montaña Occidental Astur-Leonesa, León: Celaryn; URÍA LíBANO, F., (1990). «Los cantares de boda en la montaña occidental astur-leonesa». Revista de folklore. Valladolid: Caja de Ahorros Popular de Valladolid, $n^{\circ}$. 118, pp. 120-123; PUENTE Hevia, F. De LA, (2000). El baille d'arriba: el son de la Montaña Occidental Astur-Leonesa. Lugones-Siero; GonzÁlez-Quevedo GonZÁlez, R., (2001). La fala de Palacios del Sil.Uviéu: Academia de la Llingua Asturiana. 
desde principios de la Edad Media a toda la Montaña Occidental leonesa en la diócesis de Oviedo, y así fue hasta los primeros años de la década de los 50 del presente siglo. Aunque es evidente que esta situación también era más o menos habitual en otras partes de la Península Ibérica, no por ello deja de ser un testimonio significativo.

Pasemos a continuación a estudiar las demarcaciones políticas. Ya en el siglo XIII, exactamente el 24 de marzo de 1270, fecha en la que Alfonso X otorgó la carta-puebla a los “...omes de la tierra de Laciana...", y entre una de las muchas concesiones que el rey sabio hace a los nuevos pobladores de la pola o puebla de San Mamés, estaba la facultad de hacer un mercado semanal los martes, garantizando del mismo modo la seguridad en su celebración al igual que la que gozaban los demás mercados asturianos: “...e otrosi les otorgamos que fagan y mercado cada semana en dia de martes, e que todos aquellos que y vinieren que vengan e vayan seguros, asi como a todos los otros mercados de Asturias..." 3 No sólo resulta interesante la calificación geográfica que el texto asigna a la puebla de San Mamés, como otra puebla "asturiana" mas dentro del conjunto regional, sino también el propio hecho de la fundación de la puebla dentro del programa fundacional urbano desarrollado por Alfonso X en el marco espacial de Asturias durante todo su reinado ${ }^{4}$. Asimismo nos parece significativo señalar, cómo en la misma carta-puebla se delimita el alfoz concejil, incluyéndose en el concejo de Laciana dos localidades que quedarían del lado de la divisoria de aguas de la red cantábrica, Cerredo y Degaña, que vierten aguas al Navia, lugares que posteriormente pasarían a Asturias y cuya reforma sería confirmada con la división provincial de 1833, quedando entonces el lindero en el punto de aguas vertientes del Puerto de Cerredo ${ }^{5}$. Esto nos sirve para observar y comprender que en el Medievo la divisoria de aguas de la Cordillera, no parecía tener una correspondencia tan lógica y determinante como en la actualidad para dividir el territorio entre Asturias y León, y en consecuencia, cómo estos dos lugares se consideraban parte integrante del concejo de Laciana por lo menos hasta inicios del siglo XVI.

3 RodrígueZ, J., (1981). Los Fueros del Reino de León. León: Ediciones Leonesas, T. I, p. 208.

${ }^{4}$ Para un análisis pormenorizado sobre la fundación de las pueblas en Asturias durante la Edad Media consultar la obra de Ruiz De La Peña, J. I., (1981). Las Polas asturianas en la Edad Media. Estudio y Diplomatario. Oviedo: Universidad de Oviedo.

5 Díez GonzÁlez, F. A., (1985). Memoria del antiguo y patriarcal Concejo de Laciana. León: Ediciones Leoneses, p. 96. 
A mediados del siglo XIV, en un privilegio concedido en Ávila el 2 de agosto de 1346 por Alfonso XI a los pobladores lacianiegos, observamos como el concejo de Laciana aparece ubicado dentro de la merindad de Asturias ${ }^{6}$. Y unos pocos años después, el 21 de septiembre de 1367, debido a la fidelidad que prestaba Asturias a la causa legítima del rey D. Pedro, encontramos a los concejos de Laciana y Babia en la famosa reunión celebrada en el monasterio de Santa María de Vega, confederándose junto con otros concejos y territorios asturianos en la organización de su defensa ${ }^{7}$.

Posteriormente, ya en 1485, y esta vez en el valle de Babia, existe alguna referencia en la que se enclava al concejo de Babia de Yuso en Asturias, y así se dice en una carta enviada por los Reyes Católicos a Luis Mejía, su corregidor en el Principado, como ...juan gonçalez de la majua vecino del conçejo de babia de yuso que es en el dicho prinçipado... les había informado sobre los desmanes que había cometido aquel en su persona ${ }^{8}$. Otra noticia idéntica a la anterior, la extraemos de una carta del año 1500 dirigida también al corregidor del Principado de Asturias, en la que se le ordena que proceda con justicia en los concejos de Babia de Suso y de Babia de Yuso, por que se han quejado de ciertas personas que ...se han entremetydo e entremeten a nonbrar e elegir alcalde e juezes e otros ofiçiales de los dichos conçejos contra nuestra carta e defendemyento en que mandamos que ningunos cavalleros nyn escuderos ny parientes mayores no entendiesen en las eleçiones de los ofiçios de las vyllas e logares dese dicho prinçipado... ${ }^{9}$ Incluso en fechas tardías, como en un pleito mantenido entre los vaqueiros del Principado de Asturias con Don Claudio Fernández de Quiñones, conde de Luna, se dice en el encabezamiento de una carta de comisión presentada en el año 1527 por el procurador de los vaqueiros lo siguiente: ...juan del otero por si y en nombre de los vaqueros de los conçejos de lasiana e vabia e somyedo e çerredo e dagaña e rrivas

6 ...e a los nuestros cogedores e recabdadores de las nuestras yantares de la merindat de tierra de asturias e de lasiana que es en la dicha merindat..., Archivo Quiñones Condes de Luna, (Sección pergaminos), (1434, julio, 1), doc. $n^{\circ} .36$.

${ }^{7}$ Benito Ruano, E., (1972). Las Hermandades en Asturias durante la Edad Media: Discurso de ingreso en el Instituto de Estudios Asturianos y contestación por D. Juan Uría Ríu. Oviedo: Imprenta la Cruz de Pardo y Compa , p. 33.

${ }^{8}$ A.G.S., R.G.S., 1485, abril, 28, fol. 154,(1 $\left.\mathrm{r}^{\mathrm{o}}\right)$. Una problemática que está presente a finales del siglo XV y principios del siglo XVI, son los enfrentamientos e intromisiones de los corregimientos de León y Asturias por el control político de los concejos babianos, y también de la existencia en ciertos casos, de una negativa por parte de los montañeses a no ofrecer ningún tipo de servicios a la ciudad de León.

${ }^{9}$ A.G.S., R.G.S., 1500 , mayo, 30, fol. $48,\left(1 v^{\circ}\right)$. 
de sil que son en el nuestro prinçipado de asturias de oviedo nos hizo rrelaçion... ${ }^{10}$ En este último caso, además de ubicar Laciana y Babia en Asturias, también se hace lo mismo con el vecino concejo de Ribadesil de Suso.

Igualmente no podíamos dejar de reseñar, cómo a finales del siglo XVI, y del mismo modo que hicieron otros concejos de Asturias en un novedoso proceso de redención de algunos lugares durante la Edad Moderna ${ }^{11}$, el concejo asturiano de Lena pretendió comprar en el año 1583 los lugares de Pinos y San Emiliano, ubicados en el valle leonés de Babia Baja. Pero lo que más nos interesa aquí de todo ello, fue el motivo exacto que argumentaron para hacerlo: “...el estar tan cerca del concejo y ser casi una misma cosa..."; además de otras razones no por ello menos interesantes ${ }^{12}$. Uno de los objetivos, pues, que trataba de alcanzar el concejo de Lena con esta adquisición, era evitar posibles diferencias con los canónigos de San Isidoro el Real de León y por consiguiente con sus vasallos de Pinos y San Emiliano. Esto viene a indicar en última instancia, que las barreras existentes entonces entre Asturias y León no tenían el mismo significado que las actuales, o por lo menos, para los contemporáneos de aquella época no estaban tan claramente definidas y delimitadas en este sector concreto de la Cordillera Cantábrica.

También tenemos noticias de que en el siglo XVII, fechas en las cuales todos los concejos de la Montaña Occidental están ya ubicados de forma definitiva en el distrito leonés sin ningún genero de duda, algunos de esos concejos mantuvieron un pleito sobre su facultad y libertad para proveerse de sal donde mejor les conviniese $^{13}$. Algunas partes de este pleito nos verifican lo mejores que eran las

${ }^{10}$ Archivo Histórico Nacional, [Sección Nobleza], Frías, Legajo 1524/20, (año 1557), fol. 2ro ${ }^{\circ}$.

11 Entre los motivos generales de algunos concejos asturianos para ayudar a la exención de algunos lugares o cotos enclavados dentro de ellos o en sus límites, estaban según palabras de $\mathrm{M}^{\mathrm{a}}$ Ángeles Faya Díaz las siguientes razones: "Atropellos de caballeros asturianos a concejos, monasterios y vecinos también son citados en otras circunstancias, por lo que debian ser frecuentes; esta situación explica el miedo general que había de que se convirtieran en señores jurisdiccionales", FAYA DíAZ, Ma. A., (1992). Los señoríos eclesiásticos en la Asturias del siglo XVI. Oviedo: Instituto de Estudios Asturianos, p. 294. Un análisis pormenorizado sobre la venta de los señoríos desvinculados a finales del siglo XVI en Asturias, nos lo ofrece esta autora en la obra anteriormente citada entre las pp. 281-322.

12 "son mui necesarios y de provecho para este concejo por la quietud y sosiego del partir como parte con ellos terminos y otras cosas de que podrían redundar pleitos y diferencias", FAYA DíAZ, $\mathrm{M}^{\mathrm{a}}$. A. Los señorios eclesiásticos..., p. 294 (nota 36) y p. 295.

13 “....Los concejos y vecinos de Sil de Arriba, Sil de Abajo, los Cilleros, Mataotero, Babia de Suso y de Yuso y Torrestio y Tejedo, todos ellos en la provincia de León, ante vuestra alteza, como 
relaciones, comunicaciones y cercanía con los valles asturianos que con las tierras meseteñas de León, que quedaban más lejanas y con peores infraestructuras $\operatorname{viarias}^{14}$, motivo este último por el cual algunos de los concejos de la Montaña Occidental solicitaban proveerse de sal en las salinas de Asturias y no en las de León $^{15}$.

Siendo fieles a la objetividad histórica, debemos decir que además de las menciones a la localización geográfica y política de Laciana y Babia dentro del Principado de Asturias durante la Edad Media, también aparecen otras cargadas de cierta ambigüedad. Resultan expresivas ciertas alusiones a la ubicación del valle de Babia, situándolo en ciertos momentos en algún sector indeterminado entre Asturias y León ${ }^{16}$, o al valle de Laciana, enclavándolo en una zona imprecisa entre

más convenga y mejor proceda...digo que, en el siglo pasado y por los años de 1649 se siguió un pleito en esta superioridad... y se pleiteó sobre si habia de ser facultativo y libre para estos Concejos el proveerse de la sal que necesitan donde mejor les acomode..." fragmento recogido de ÁlvarEZ Rubio, J., (1994). Por el país de Las Brañas: Laciana, Omaña, Babia, Palacios de Sil, Somiedo. León: Ediciones Leonesas, pp. 39-40.

14

“...que estos concejos se hallan situados en las montañas de León, confinantes y vertientes al Principado de Asturias, el que más, de doce leguas por camino cómodo y seguro. Y, por el contrario, el concejo más inmediato a las Pozas de la Sal de León está a más de cuarenta leguas por camino sumamente áspero, lleno de puertos peligrosos, cubiertos de nieve los ocho meses del año, con muchos arroyos sin puente e insuperables en las avenidas tan frecuentes como copiosas y perjudiciales, que hacen detenerse forzosamente a carros y caballerias con pérdida, muchas veces, de todo ello...", Álvarez Rubio, J. Por el País de las Brañas..., p. 40.

15 A las consideraciones mencionadas anteriormente que motivaron el citado pleito, se añade además: “...el hecho de que son todos estos pueblos mucho más miserables que los del Concejo de Laciana, por ser éste último un paso o camino de herradura hacia las dos Castillas y Asturias y por hallarse aquellos fuera de todo tránsito o comercio, de donde se sigue la escasez de dinero y de medios para proveerse de sal y pan. Penuria que salvan, en parte, surtiéndose de aquellos asturianos que acuden a vendérsela por las puertas, conmutándola o pagándola con los géneros que producen en el país, como son las mantecas, quesos, lino y demás que producen..." estampa de una tierra de montaña aislada y fragosa que coincide asimismo con lo que hemos observado para los siglos de la Edad Media, Álvarez Rubio, J. Por el País de las Brañas..., p. 40.

16

....es tierra apartada desa dicha çibdad (León) e del dicho prinçipado de asturias..., [A.G.S., R.G.S., 1498, julio, 10 , fol. $\left.106,\left(1 \mathrm{r}^{\circ}\right)\right]$; ...que entre ese reyno y el principado de asturias de oviedo ay dos concejos..., Archivo Histórico Provincial de León,doc. no 547, Legajo 17, (1539, marzo, 30),fol. $1 \mathrm{r}^{\mathrm{o}}$. 
Galicia, Asturias y León ${ }^{17}$, o por el contrario, emplazando a los concejos de una forma precisa en un territorio determinado ${ }^{18}$.

En resumen, hemos comprobado cómo a lo largo de la Edad Media, la ubicación de este sector sur-occidental del macizo astur-leonés ha gravitado entre Asturias y León, dándose el caso entre los contemporáneos de entonces, de situar los concejos mayores de la Montaña Occidental bien en Asturias, en León o en un lugar no concretizado entre ambos territorios. En último caso, observamos como toda la Cordillera Cantábrica en sí misma, constituía y constituye el escenario de un territorio que vincula, más que desune, dos espacios pertenecientes a un mismo tronco cultural con todas las implicaciones que de ello se derivan ${ }^{19}$.

\section{FUENTES INÉDITAS:}

ARCHIVO QUIÑONES CONDES DE LUNA. ARCHIVO HISTÓRICO PROVINCIAL DE LEÓN.

ArChivo General De Simancas. Secciones: Registro General del Sello, Consejo Real, Cámara de Castilla (Memoriales / Pueblos).

ARCHIVO Histórico NACIONAL. Sección Nobleza.

17 ...que es en el estremo del reyno de galizia y del prinçipado de asturias y del reyno de leon..., A.G.S., Consejo Real, Legajo 126, fol.16, (año 1532), fol. 1 $1 \mathrm{r}^{\mathrm{0}}$.

18 Es el caso de los concejos de Babia, que se dice están en: ...termyno de la dicha çibdad (León)..., [A.G.S., R.G.S., 1498, julio, 10, fol. 158, (1 $\left.\mathrm{r}^{\mathrm{o}}\right)$ ]; ...en la jurediçion de la dicha çibdad (León)..., [AG.S., R.G.S., 1527, octubre, 5, fol. 1 10]; ...en las montañas de leon..., [A.G.S., Cámara de Castilla (Pueblos), Legajo 3, doc. $\mathrm{n}^{\circ} 5$ bis (año 1505), fol. 1 $\left.1 \mathrm{v}^{\circ}\right]$; o del valle de Laciana: ...que por parte del conçejo e omes buenos de lasiana que es en tierra de leon en el obispado de oviedo..., [Archivo Quiñones Condes de Luna., (Sección pergaminos), (1434, julio, 1), doc. no. 36]. Menos género de dudas creaba la localización de otros concejos como por ejemplo el de Omaña, situado al sur de los valles babianos: ...concejo de omaña que es en el reyno de leon..., A.G.S., Cámara de Castilla (Memoriales), Legajo 205, doc. $n^{\circ} 43$, (año 1513), fol. 1r r $^{\circ}$

${ }^{19}$ Esas analogías existentes entre Asturias y León más que sus diferencias, han sido ya apuntadas por algunos autores como León Martín-Granizo a mediados del siglo XX, para quien estas dos provincias limítrofes “...aunque son varias en su psicología, como hijas de otro medio geográfico, tienen muchas características comunes que las diferencian de las demás regiones españolas...”; a esta reflexión, añade otra en la misma línea pero expresada en primera persona: “...Pero nos une además, algo que yo creo más fuerte que los lazos materiales: la devoción a la tierra, el sentimiento de la tierra, el arraigo a la misma...", MARTíN-GRANIzO, L., (1955). «De León a Oviedo». Boletín del Instituto de Estudios Asturianos. Oviedo: Instituto de Estudios Asturianos, no. 24, pp. 121-122. 


\section{BIBLIOGRAFÍA Y FUENTES IMPRESAS:}

Álvarez PÉrez, G., (1985). El habla de Babia y Laciana, reed., León: Ediciones Leonesas.

Álvarez Rubio, J., (1994). Por el país de Las Brañas: Laciana, Omaña, Babia, Palacios de Sil, Somiedo. León: Ediciones Leonesas.

Benito RuAnO, E., (1972). Las Hermandades en Asturias durante la Edad Media: Discurso de ingreso en el Instituto de Estudios Asturianos y contestación por D. Juan Uría Ríu. Oviedo: Imprenta la Cruz de Pardo y Compa

DíEz GonzÁlez, F. A., (1985). Memoria del antiguo y patriarcal Concejo de Laciana. León: Ediciones Leoneses.

FAYA DíAZ, $M^{\mathrm{a}}$. A., (1992). Los señoríos eclesiásticos en la Asturias del siglo XVI. Oviedo: Instituto de Estudios Asturianos.

García Larragueta, S. A., (1962). Colección de documentos de la Catedral de Oviedo. Oviedo: Instituto de Estudios Asturianos.

GonzÁlez-Quevedo GonzÁlez, R., (2001). La fala de Palacios del Sil.Uviéu: Academia de la Llingua Asturiana.

Marentes Álvarez, C. / CRiado Placín, L., (1987). (Grabación sonora realizada por la "Sociedad San Miguel de Bailes y costumbres de Laciana"), $A$ xeito: música, canciones y bailes de la Montaña Occidental Astur-Leonesa, León: Celaryn.

MARTín-Granizo, L., (1955). «De León a Oviedo». Boletín del Instituto de Estudios Asturianos.Oviedo: Instituto de Estudios Asturianos, $\mathrm{n}^{\circ} .24$.

Puente Hevia, F. De LA, (2000). El baille d'arriba: el son de la Montaña Occidental Astur-Leonesa. Lugones-Siero.

RodrígueZ, J., (1981). Los Fueros del Reino de León. León: Ediciones Leonesas, T. I.

Rodríguez Cosmen, M., (1982). El pachxuezu, habla medieval del occidente Astur-Leonés, León: Lebrija.

Ruiz De La PeÑA, J. I., (1981). Las Polas asturianas en la Edad Media. Estudio y Diplomatario. Oviedo: Universidad de Oviedo.

SÁNCHEZ BADIOLA, J. J. (2004). Las armas del reino y otros estudios de historia leonesa. León: Diputación Provincial de León.

URÍA LÍBANO, F., (1990). «Los cantares de boda en la montaña occidental asturleonesa». Revista de folklore. Valladolid: Caja de Ahorros Popular de Valladolid, ${ }^{\circ} .118$. 